\title{
Personal best goals in alignment with environmental perceptions of classroom activities
}

\author{
Alishahi, Mohammad Hassan \\ Imam Reza International University, Mashhad, Iran (m.halishahi@yahoo.com) \\ Ghanizadeh, Afsaneh $\triangle$ \\ Imam Reza International University, Mashhad, Iran (a.ghanizadeh@imamreza.ac.ir)
}

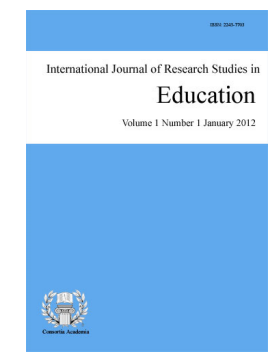

ISSN: 2243-7703 Online ISSN: 2243-7711

Received: 27 April 2017

Available Online: 26 May 2017

Revised: 4 May $2017 \quad$ Accepted: 24 May 2017

OPEN ACCESS

\section{Abstract}

One of the objectives of any educational endeavor is helping learners to adopt set of personal goals for their achievement. This is known as personal best (PB) goals. It is also believed that PB can fluctuate in line with external factors. The aim of this study is to study these goals in association with students' perception of the learning environment. To do so, 143 students studying in high schools of Mashhad completed two questionnaires: the first one was the translated version of Personal Best Questionnaire designed by Martin (2006) measuring specific, challenging, competitive and self- improvement goals. The second one was the Persian version of 'Students Perceptions of Classroom Activities' scale designed and validated by Gentry and Gable (2001) and translated to Persian and revalidated by Ghanizadeh and Jahedizadeh (2015). It contains four dimensions (interest, challenge, choice, and joy). The results indicated that all four subscales of students' perception fit the data well and significantly predicted personal goals. Furthermore, there were positive associations between perceptions of classroom activities and the subscales of PB. The highest relationship was between challenging goals and perceptions of challenge followed by the correlation between students' choice and personal goals.

Keywords: language learners; PB goals; students' perceptions of classroom activities; CFA 


\section{Personal best goals in alignment with environmental perceptions of classroom activities}

\section{Introduction}

Goals play an important role in students' academic development. Different types of goal construction have been suggested in psycho educational research such as goal setting, goal orientation, and goal structures (Maehr \& Zusho, 2009). One of the most recently proposed goals represent the goals which are best personalized. Personal best (PB) goals are defined as specific, challenging, competitively self-referenced targets to which students try to match or exceed a previous best (Martin \& Elliot, 2015). Performing better on the school work than previous efforts and increased learning are examples of such ends. Martin (2011) proposed PB goals as an additional type of growth oriented goal toward improving one's previous best such as spending more time for working on assignments than previous efforts. They may also refer to a learning environment where emphasis is on the outperforming of one's previous best and improving personal efforts for academic growth.

In educational domain, Elliot and Sheldon (1997) outlined four representations of goals: 1. Task specific goals (like completing a task as an assignment) which are guidelines for performance. 2. Situation specific goals which reflect the purpose and reasons of performing; performing better than others in a class is an example of this goal. 3. Personal goals which involve more general ends like one's improving at the end of the course. For example, a student improves at the end of the term. 4. The image of oneself for the future such as the achieving revenue after graduation; it can be assumed as a kind of challenge with themselves. The first two goals encompass PB goals; because task specific goals provide students with clear information about what they want to achieve and situation specific goals provide students with the reasons for achieving a particular outcome. Moreover, they are personalized elements that distinguish them from other goals and make them powerful means of motivation for self-improvement which builds on previous levels of performance or attainment. For this, the level of challenge prescribed by PB should be higher than the level of previous best level of performance.

Achievement goal theory is a relevant concept for studying PB goals. It is an integrated pattern of belief attributions and affects the intentions of behavior (Ames, 1992). According to Elliot (2005), this theory is grounded on four dimensions: first, mastery goals focused on learning environment where personal learning and effort are valued; it is an end for developing ability. Second, performance goals focused on out performance and learning environment where competition over other students is emphasized. It is a goal for proving ability. In other words, mastery goals focus on tasks whereas performance goals focus on showing the competence over others. Third, mastery avoidance goal which aims to avoid misunderstanding; and last, performance avoidance goals aiming to avoid poor performance of competitive tasks. Wolters (2004) proposed that students learn for the sake of learning by their mastery goals, and because of demonstrating higher ability by their performance goals. Of course, there are some differences between these two perspectives; for example mastery goals are usually task based while PB goals seems to be self-based (Elliot, 2005). It means PB goals are set in relation to self, whereas performance goals are set in relation to others. According to Yu and Martin (2014), there are practical strategies for amplifying the effect of PB goals setting on students' achievement growth. For example, instructors may draw their attention toward both process and outcome oriented PB goals resulting in improving their achievement.

In the context of classroom or assessment programs, some students may benefit from the progress of achieving a personal goal and growth for their academic development. According to Locke and Latham (2002), students' personal goals affect their achievement through different mechanism. They can motivate and facilitate further commitment and pursue other goals. Personal goals may help an individual to draw their attention and effort toward the tasks and activities relevant to the goals. They can also lead to the knowledge and skills required for attaining the ends and because of energizing capacity, encourage students for further goal achievement. Moreover, they create a gap between the current and desired attainment and motivate them for 
reducing this dissonance. Locke and Latham also proposed a model for achieving personal goals. They pointed specific and difficult goals lead to improvement, performance, and achievement. In other words, task complexity and goal difficulty can be a link between the ends and their achievement. So, challenging goals create pressure for performing and result in success. Hulleman, Schrager, Bodmann, and Harackiewicz (2010) did a met analysis on achievement goals. The results indicated that personal goals can predict achievement and success if they are challenging and specific.

PB goals have been associated with adaptive outcomes including, engagement, persistence, and homework competition (Martin, 2012). The review of the previous research indicated that achievement goal can act as a nexus between either personal or contextual goal or motivational outcomes (e.g., Diseth \& Kobbeltvedt, 2010). In 2014, Martin conducted a study and proposed that individual mastery and PB goals uniquely predicted their motivation and engagement outcome. This research has identified that perceived goals, which refer to students' perception of the goals in their learning environment, and individual goals, which include mastery and performance goals, are associated with academic outcomes. On the other hand, classroom support and guidance facilitate students' goal to be motivated for the later tries. However, as Urdan and Schoenfelder (2006) pointed, it is not clear to what degree students' personal goals color their perceptions which are promoted by the teacher or themselves during their everyday classroom activity.

The review of classroom environment literature reveals there has been an enhancing interest for finding the role of classroom context in increasing students' learning. Fraer (1986) argued the classroom perception can be viewed as a determinant of behavior implying that the perceptions might affect beliefs, goals, and strategies use in classroom. For example, teachers who assign meaningful tasks create an environment with a more task focused goal structure so students are more likely to adopt a personal task focused goal orientation. However, if students know they are recognized on the basis of better grades or in relation to others, they would adopt personal extrinsic goal orientation or relative ability (Pintrich \& Schrauben, 1992). It means students' personal goals are affected by their perceptions of the classroom goal structure. These personal ends are related to the strategies students try to use (Nelom, 1998).

Teachers play a vital role in conceptualization of classroom activity. They create social environment for learning. They do not choose the class but control the climate constructed with students. The classroom environment shapes the teacher's relation with students (Ghanizadeh \& Moafian, 2010; Ghanizadeh \& Royaei, 2014). Teachers who are successful in establishing effective classroom climates create more time for learning, involving more students in the activities, and help them to become self-regulating. Teachers usually pay more attention to the assessment of academic achievement and devote little concentration on the factors related to students' pattern of learning or performance. One of the best ways for accomplishing a positive learning environment is having a good class management plan like having clear rules or preventing problems to happen. In 2006, Doyle suggested classrooms are multidimensional; they are crowded with people, tasks, procedures, goals, and students' ability. This is an evidence for showing that teacher's perception can influence on students' learning.

There has been an increasing interest in finding the role of classroom context in students' goal, their conceptualizations and strategies they use. Goal theory researchers like Eccles et al. (1993) found a relationship between goals adopted in a class and classroom environment. Goal theory is a concept which involves the assumption that motivational orientations can be influenced by classroom context. In other words, the characteristics of classroom environment such as teacher's, peer support or teacher's interpersonal style may affects students' motivation. Ames and Archer (1988) suggested students' motivational orientation was influenced by certain dimensions of classroom context such as tasks, teacher's authority, grouping, evaluation, time and etc. it reveals teachers hold great effects over the students they encounter and the classroom environment does play a significant role in the attitudes adopted by the students (Anderman \& Midgley, 1997). This theory leads us to expect instructional practices can pull for motivational patterns. Gender and ethnic differences have also been established; suggesting a possibility of cultural differences in classroom environments 
Alishahi, M. H., \& Ghanizadeh, A.

and goal orientations (Kaplan \& Maehr, 1999).

The purpose of this study is to find the relationship between students' perception of the classroom environment and their personal best (PB) goals . In so doing, a model is proposed to examine for the structural relations between $\mathrm{PB}$ and perceptions of classroom activities.

\section{Method}

\subsection{Participants}

One hundred forty-three students studying in high schools of Mashhad participated in this study. Their age varied from 13 to 18 . The participants were randomly selected from twelve classes. 70 percent of them were boys and the rest were girls. Students were asked to complete the questionnaire on their own and return it to the teacher at the end of the class.

\subsection{Instruments}

PB Questionnaire - To explore student Personal Best goals, the researchers utilized the Persian version of the Personal Best Questionnaire designed by Martin (2006) and translated to Persian by Jahedizadeh and Ghanizadeh (forthc.). The questionnaire comprises 16 items measuring four different types of goals namely; specific goals (4 items), challenging goals (4 items), competitively self-referenced goals (4 items), and self-improvement goals (4 items) via a 5-point Likert type response format (completely disagree, disagree, to some extent agree, agree, and completely agree). The sample items for the first set of goals are I set specific goals to aim for in my schoolwork and I get it clear in my head what specific goals I'm aiming for in my schoolwork. The sample statements of the second goals include I set challenging goals for myself in my schoolwork and I like to work towards challenging goals in my schoolwork. The sample items of the third set also consist of I am in competition with myself more than with other students and I compete with my own previous marks more than I compete with other students' marks. The last set of items also involve sample items of When I do my schoolwork I try to do it better than I've done before and When I do my schoolwork I try to get a better result than I've got before. The Cronbach's alpha of the Personal Best Questionnaire was acceptable ranging from .77 to .90 regarding sixteen items (Martin, 2006).

Perceptions of Class Activity Questionnaire - To assess students' perceptions of classroom activities, the researchers used the translated version of 'Students Perceptions of Classroom Activities' scale designed and validated by Gentry and Gable (2001) which was translated to Persian and validated by Ghanizadeh and Jahedizadeh (2015a). Validity evidence for construct interpretation was investigated through confirmatory factor analysis. A chi-square/df ratio (2.38) and the RMSEA (. 062) as well as the GFI (. 78) were indicative of model fit. Furthermore, all items had accepted factor loadings. The Cronbach's alpha estimates for each perception ranged from. 71 to .80 . (interest $=.86$, challenge $=.73$, choice $=.71$, joy $=.79$ ).

The 'Students Perceptions of Classroom Activities' instrument contains 31 statements evaluating four dimensions (interest, challenge, choice, and joy). The scale measures the four dimensions via a 5-point Likert-type response format (never, seldom, sometimes, often, and always). The participants were provided with directions on how to complete the scale. Sample items for 'interest' dimension included: 1) What I do in my class fits my interests, and 2) I have an opportunity to work on things in my class that interest me. Sample items for 'challenge' dimension are: 1) I find the work in this class demanding, and 2) I am challenged to do my best in class. Sample items include in 'choice' dimension are: 1) I can choose materials to work with in the class, and 2) I can choose an audience for my product. Sample items for 'joy' dimension are: 1) The activities I do in my class are enjoyable, and 2) I like the projects I work on in my class. 


\subsection{Procedure}

This study was undertaken in five high schools (Nasr, Novin, Noavaran and two branches of Imam Reza) in Mashhad, Iran. Random sampling was used for collecting data and all the participants kindly accepted to participate in the current study. The researchers explained the purpose of completing the questionnaires for the participants and asked them not to write their names. The data collection took place between April and June 2016.

\section{Results}

Table 1 presents descriptive statistics of perceptions of classroom activities (interest, challenge, choice, and joy) among the participants. As the Table shows, among the four perceptions, challenge received the highest mean $(M=30.62, S D=6.51)$.

Table 1

Descriptive Statistics of Students' Perceptions of Classroom Activities

\begin{tabular}{llllll}
\hline & $\mathrm{N}$ & Minimum & Maximum & Mean & Std. Deviation \\
\hline Interest & 143 & 8.00 & 40.00 & 29.11 & 6.27 \\
Challenge & 143 & 11.00 & 39.00 & 30.62 & 6.51 \\
Choice & 143 & 182.00 & 35.00 & 22.81 & 5.64 \\
Joy & 143 & 7.00 & 35.00 & 22.90 & 5.78 \\
Valid N (listwise) & 143 & & & & \\
\hline
\end{tabular}

Descriptive statistics of PB goals and its corresponding subscales (specific goals, challenging goals, competitively self-referenced goals, self-improvement goals) are represented in Table 2. As the Table reveals, self-improvement goals and competitive self-referenced goals obtained the highest mean scores: completive goals $(M=15.65, S D=3.67)$, self-improvement goals: $(M=15.53, S D=4.99)$.

\section{Table 2}

Descriptive Statistics of PB Goals and its Sub-scales

\begin{tabular}{lllllll}
\hline & $\mathrm{N}$ & Possible range & Minimum & Maximum & Mean & SD \\
\hline Specific Goals & 143 & $4-20$ & 4.00 & 20.00 & 14.56 & 2.89 \\
Challenging Goals & 143 & $4-20$ & 4.00 & 26.00 & 14.34 & 3.32 \\
Competitive SR Goals & 143 & $4-20$ & 4.00 & 42.00 & 15.65 & 3.67 \\
Self-improve Goals & 143 & $4-20$ & 4.00 & 58.00 & 15.53 & 4.99 \\
PB & 143 & $20-80$ & 16.00 & 136.00 & 58.00 & 12.63 \\
\hline
\end{tabular}

The reliability estimates of the variables variable computed via Cronbach's alpha are as follows: interest $(\alpha=.75)$, challenge $(\alpha=.81)$, choice $(\alpha=.79)$, joy $(\alpha=.80)$ and $\operatorname{PB}(\alpha=.83)$.

Structural equation modeling (SEM) utilizing the LISREL 8.50 statistical package was performed to investigate the structural relations between PB and perceptions of classroom activities. In this study, perceptions of classroom activities were selected as the independent variable, the effect of which on PB goals was explored. To evaluate the model fit, the following fit indices were scrutinized: the chi square/df ratio which should be lower than 2 or 3, the Normed Fit Index (NFI), the Comparative Fit Index (CFI), and the Good Fit Index (GFI) with the cut value greater than .90, and the Root Mean Square Error of Approximation (RMSEA) of about .06 or .08 (Schreiber et al., 2006 as cited in Ghanizadeh \& Rostami, 2015). The structural model is presented in Figure 1. As Figure 1 reveals, the chi-square/df ratio (2.60), the RMSEA (0.08) and the NFI=.90 all reached the acceptable fit thresholds. Overall, it can be concluded that the proposed model had a good fit with the empirical data. It was also found that, all perceptions positively and significantly predicted PB goals: interest $(\beta=.45, t=$ $6.02)$, challenge $(\beta=.52, t=7.23)$, choice $(\beta=.51, t=6.96)$, and joy $(\beta=.44, t=5.48)$. 


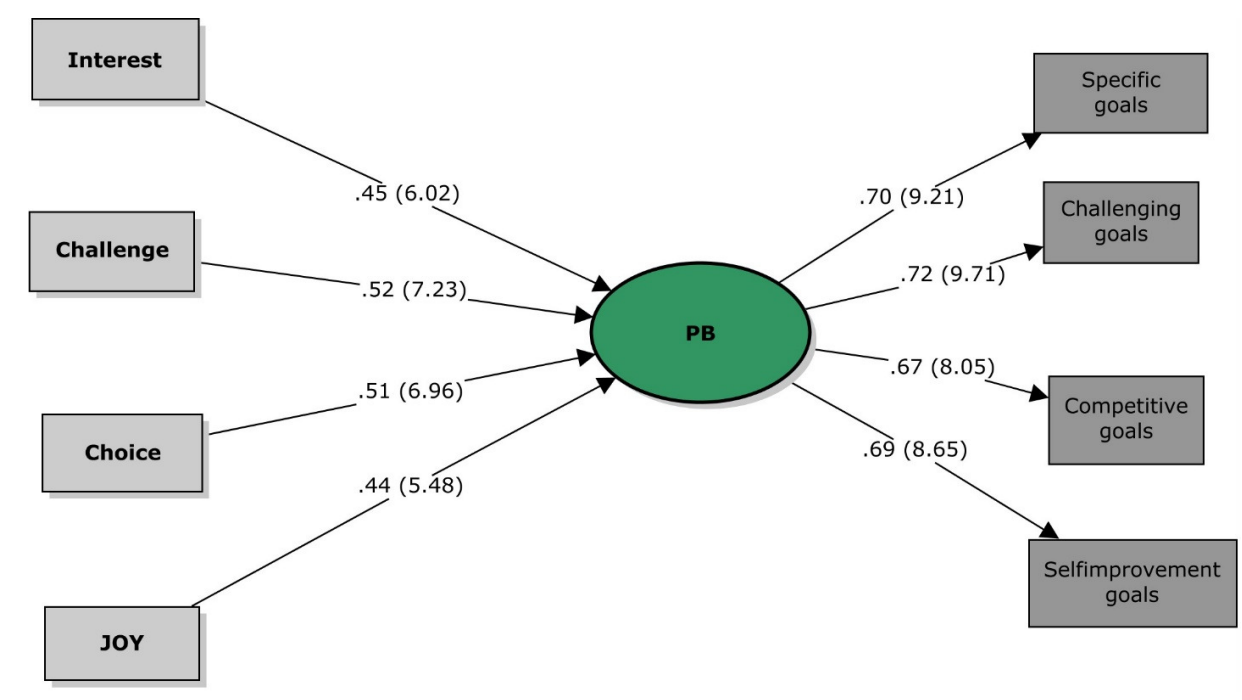

$\chi 2=523.79, d f=201.45, R M S E A=0.08, N F I=0.90$

Figure 1. The schematic representation of the association between perceptions and PBs.

To explore the relationship between perceptions of classroom activities and the sub-scales of PB, a correlation coefficient was run. The results are presented in Table 3. As can be seen, all the four goals positively and significantly correlated with the four perceptions. The highest correlation is observed between challenging goals and perception of challenge $(r=0.62, p<0.05)$. The second higher correlation was found between competitively self-referenced goals and challenge $(r=0.61, p<0.05)$. The two perceptions of challenge $(r=$ $0.59, p<0.05)$ and choice $(r=0.58, p<0.05)$ had higher correlations with PBs.

Table 3

The Correlation Coefficients between Perceptions and PB Goals

\begin{tabular}{llllllllll}
\hline & 1 & 2 & 3 & 4 & 5 & 6 & 7 & 8 & 9 \\
\hline 1. Interest & 1.00 & & & & & & & & \\
2. Challenge & $.77^{* *}$ & 1.00 & & & & & & & \\
3. Choice & $.79^{* *}$ & $.70^{* *}$ & 1.00 & & & & & & \\
4. Joy & $.81^{* *}$ & $.74^{* *}$ & $.82^{* *}$ & 1.00 & & & & & \\
5. Specific goals & $.49^{* *}$ & $.51^{* *}$ & $.50^{* *}$ & $.48^{* *}$ & 1.00 & & & & \\
6. Challenging goals & $.41^{* *}$ & $.62^{* *}$ & $.59^{* *}$ & $.42^{* *}$ & $.65^{* *}$ & 1.00 & & & \\
7. Competitive SR goals & $.50^{* *}$ & $.61^{* *}$ & $.59^{* *}$ & $.42^{* *}$ & $.46^{* *}$ & $.66^{* *}$ & 1.00 & & \\
8. Self-improvement goals & $.50^{* *}$ & $.58^{* *}$ & $.57^{* *}$ & $.52^{* *}$ & $.36^{* *}$ & $.69^{* *}$ & $.81^{* *}$ & 1.00 \\
9. PB goals & $.43^{* *}$ & $.59^{* *}$ & $.58^{* *}$ & $.45^{* *}$ & $.68^{* *}$ & $.68^{* *}$ & $.90^{* *}$ & $.90^{* *}$ & 1.00 \\
\hline Note $* *$ Correlation is significant at the level of 0.05 & & & & & & & & &
\end{tabular}

\section{Discussion and Conclusions}

The aim of the present study was to structure a model for students' perception of the class activity (interest, challenge, choice, and joy) and the subscales of personal best which can be divided into different goals (specific, challenging, competitive, and self- improvement). According to proposed model, all four perceptions predicted the goals positively and significantly. Moreover, a correlational analysis was run to find the relationship between personal best and students' perception of class activity. It was found that all four goals had positive and significant relationship with perceptions.

Based upon the model, challenge has the most impact on PB goals. It implies if the class is more challenging, students strive for more self-improvement goals. This study, to some extent, is in line with previous research. For example, Ozkal, Tekkaya, Cakiroglu, and Sungur (2009) conducted a study to conceptualize a model for the 
relationships among learning environment and epistemological beliefs. It means students may be satisfied and sophisticated in some approaches but not in others. They found that students who are satisfied and find relevance in their studies, view a class as challenging and try to improve their comprehension. This improvement is a goal for them to achieve. Hacieminoglu (2016) did a research for finding students' attitudes toward meaningful learning. According to this study, students' attitudes about learning environment positively correlated with their goal orientation and self-efficacy. If the environment of the learning makes the students more satisfied, they will set more specific goals for themselves to have a meaningful learning rather than rote learning (Ghanizadeh \& Jahedizadeh, 2015b). This meaningful learning results in achieving better scores in their class. So, the will be more aware of their own ability for learning new information. Martin and Liem (2010) suggested that by making the class more challenging than what the students previously achieved and helping them to develop strategies; they will personalize their academic goals.

The current study also demonstrated that choice in the class is another important factor that should take into account for having personalized goals. Choice is a factor that is entails planning and self-monitoring, two facets of self-regulation. Zimmerman (2000) defined self-regulated learners are aware of their own learning and involve themselves in specific and self-initiated process. They also set goals and monitor themselves. They select activities they do and create environment to optimize learning. They seek places where they are more likely to choose and learn. Ghanizadeh and Alishahi (2016) also found a positive high significant relationship between choice and students' self-regulation. Learners will be more self-regulated by having more choice in the class. It can be concluded that by providing more choice in the learning environment, we can have self-regulated students who are setting personalized goals for their academic achievement. Martin (2006) has also contended that PB has a self-improvement orientation. Students who are in competition with themselves or their own previous performance are more liable to academic improvement. On the other hand, they attain the energizing properties for their own personal goals. Given the relevance of choice, self-regulation and personal goals, it can be concluded that if students have more choice in the class activities, they will be more self-regulated and set more self-improvement goals for themselves in their academic sphere.

According to our model, interest and joy were also positive predictors of PB goals. Jang et al. (2010) noted that teachers usually depend on three practices to establish an interesting component for their lessons in order to provide a set of goals in their class. The first one is outlining a framework that students are expected to act by clear and easily understood directions. In this way, teachers make the components more enjoyable for learners, and make them more interested in participating in the class activities. The next one is guiding students during daily tasks; by supporting students step by step, students will get engaged and the class will be more enjoyable. So, students will feel capable of their learning objectives. Third, instructors provide informational competence feedback. By this, students realize that their actual potential and the steps they need to take for further developing of the skills. These three factors pave the way for learners to set personal goals for their academic achievement.

Aligned with previous research (e.g., Mucherah \& Frazier, 2013), this study demonstrated the importance of students' perception of class activity in setting goals. Mouratidis et al (2013) assumed the more teachers provide interesting materials for learning and make the context of the class more challenging and enjoyable, the more these learners experience positive attitudes toward the class and set more self-fulfilling goals for their language achievement. In other words, well -structured learning environment which is challenging, interesting, enjoyable, and versatile facilitate effective learning and promote their self-improvement goals.

\section{References}

Ames, C. (1992). Classrooms: Goals, structures, and student motivation. Journal of Educational Psychology, 84, 261-271. https://doi.org/10.1037/0022-0663.84.3.261

Ames, C., \& Archer, J., (1988). Achievement goals in the classroom: Students' learning strategies and motivation process. Journal of Educational Psychology, 80(3), 260-267. 
Alishahi, M. H., \& Ghanizadeh, A.

https://doi.org/10.1037/0022-0663.80.3.260

Anderman, E. M., \& Midgley, C. (1997). Changes in achievement goal orientations, perceived academic competence, and grades across the transition to middle level schools. Contemporary Educational Psychology, 22, 269-298. https://doi.org/10.1006/ceps.1996.0926

Diseth Å., \& Kobbeltvedt, T. (2010) A mediator analysis of achievement motives, goal orientations, learning strategies and academic achievement. British Journal of Educational Psychology, 80, 671-687. https://doi.org/10.1348/000709910X492432

Doyle, W. (2006). Classroom organization and management. In M. C. Wittrock (Ed.), Handbook of Research on Teaching (3rd ed.). New York: Simon and Schuster.

Eccles, J. S., Wigfield, A., Harold, R., \& Blumenfeld, P. B. (1993). Age and gender differences in children's selfand task perceptions during elementary school. Child Development, 64, 830-847. https://doi.org/10.2307/1131221

Elliot, A. J. (2005). A conceptual history of the achievement goal construct. In A. J. Elliot \& C. S. Dweck (Eds.), Handbook of competence and motivation (pp. 52-72). Guilford Publications.

Elliot, A. J., \& Sheldon, K. M. (1997). Avoidance achievement motivation: A personal goals analysis. Journal of Personality and Social Psychology, 73, 171-185. https://doi.org/10.1037/0022-3514.73.1.171

Gentry, M., \& Gable, R.K. (2001a). My class activities: A survey instrument to assess students' perceptions of interest, challenge, choice and enjoyment in their classrooms (Instrument). Mansfield Center, CT: Creative Learning Press.

Ghanizadeh, A., \& Alishahi, M. H. (2016). The bonds between EFL learners' perceptions of classroom activities, self-regulatory skills, and language achievement. International Journal of Educational Investigations, $3(2), 72-85$.

Ghanizadeh, A., \& Jahedizadeh, S. (2015a). An exploration of EFL learners' perceptions of classroom activities and their achievement goal orientations. International Journal of Research Studies in Education, 4 (3), 33-45. https://doi.org/10.5861/ijrse.2015.1032

Ghanizadeh, A., \& Jahedizadeh, S. (2015b). Teacher burnout: A review of sources and ramifications. British Journal of Education, Society \& Behavioural Science, 6(1), 24-39.

Ghanizadeh, A., \& Moafian, F. (2010). The role of EFL teachers' emotional intelligence in their success. ELT Journal, 64(4), 424-435. https://doi.org/10.1093/elt/ccp084

Ghanizadeh, A., \& Rostami, S. (2015). A Dörnyei-inspired study on second language motivation: A cross-comparison analysis in public and private contexts. Psychological Studies, 60(3), 292-301. https://doi.org/10.1007/s12646-015-0328-4

Ghanizadeh, A., \& Royaei, N. (2015). Emotional facet of language teaching: Emotion regulation and emotional labor strategies as predictors of teacher burnout. International Journal of Pedagogies and Learning, 10(2), 139-150. https://doi.org/10.1080/22040552.2015.1113847

Hacieminoglu, E. (2016). Elementary school students' attitude toward science and related variables. International Journal of Environmental \& Science Education, 11(2), 35-52.

Hulleman, C. S., Schrager, S. M., Bodmann, S. M., \& Harackiewicz, J. M. (2010). A meta analytic review of achievement goal measure: Different labels for the same constructs or different constructs with similar labels? Psychological Bulletin, 136(3), 422-449. https://doi.org/10.1037/a0018947

Jang, H., Reeve, J, \& Deci, E. L. (2010). Engaging students in learning activities: It is not autonomy support for structure but autonomy support and structure. Journal of Educational Psychology, 102(3), 588-600. https://doi.org/10.1037/a0019682

Kaplan, A., \& Maehr, M. L. (1999). Achievement goals and student well-being. Contemporary Educational Psychology, 24, 330-358. https://doi.org/10.1006/ceps.1999.0993

Locke, E. A., \& Latham, G. P. (1990). A theory of goal setting and task performance. Englewood Cliffs, NJ: Prentice-Hall.

Locke, E. A., \& Latham, G. P. (2002). Building a practically useful theory of goal setting and task motivation: A 35-year odyssey. American Psychologist, 57, 705-717. https://doi.org/10.1037/0003-066X.57.9.705

Maehr, M. L., \& Zusho, A. (2009). Achievement goal theory: The past, present, and future. In K. R. Wentzel \& A. 
Personal best goals in alignment with environmental perceptions of classroom activities

Wigfield (Eds.), Handbook of motivation in school (pp. 77-104). New York: Taylor Francis.

Martin, A. J. (2006). Personal bests (PBs): A proposed multidimensional model and empirical analysis. British Journal of Educational Psychology, 76, 803-825. https://doi.org/10.1348/000709905X55389

Martin, A. J. (2011). Personal best (PB) approaches to academic development: Implications for motivation and assessment. Educational Practice and Theory, 33, 93-99. https://doi.org/10.7459/ept/33.1.06

Martin, A. J. (2012). The role of Personal Best (PB) goals in the achievement and behavioral engagement of students with ADHD and students without ADHD. Contemporary Educational Psychology, 37, 91-105. https://doi.org/10.1016/j.cedpsych.2012.01.002

Martin, A. J. (2014). Implicit theories about intelligence and growth (personal best) goals: Exploring reciprocal relationships. British Journal of Educational Psychology, 85(2), 207-223. https://doi.org/10.1111/bjep.12038

Martin, A. J., \& Liem, G. A. (2010). Academic personal bests (PBs), engagement, and achievement: A cross-lagged panel analysis. Learning and Individual Differences, 20, 265-270. https://doi.org/10.1016/j.lindif.2010.01.001

Mouratidis, H., Islam, S., Kalloniatis, C., \& Gritzalis, S. (2013). A framework to support selection of cloud providers based on security and privacy requirements. Journal of Systems and Software, 86(9), 2276-2293. https://doi.org/10.1016/j.jss.2013.03.011

Mucherah, W., \& Frazier, A. D. (2013). How teachers perceive their classroom environments and student goal orientation: A look into high school biology classrooms in Kenya. British Journal of Education, Society \& Behavioural Science, 3, 1-17. https://doi.org/10.9734/BJESBS/2013/2413

Pintrich, P. R., \& Schrauben, B. (1992). Students' motivational beliefs and their cognitive engagement in classroom academic tasks. In D. H. Schunk \& J. L. Meece (Eds.), Student perceptions in the classroom (pp. 149-183). Hillsdale, NJ: Erlbaum.

Schreiber, J. B., Amaury, N., Stage, F. K., Barlow, E. A., \& King, J. (2006). Reporting structural equation modeling and confirmatory factor analysis results: A review. Journal of Educational Research, 99(6), 323-337. https://doi.org/10.3200/JOER.99.6.323-338

Urdan, T., \& Schoenfelder, E. (2006). Classroom effects on student motivation: Goal structures, social relationships and competence beliefs. Journal of School Psychology, 44(5), 331-349. https://doi.org/10.1016/j.jsp.2006.04.003

Wolters, C. (2004). Advancing achievement goal theory: using goal structures and goal orientations to predict students' motivation, cognition, and achievement. Journal of Educational Psychology, 96, 236-250. https://doi.org/10.1037/0022-0663.96.2.236

Yu, K., \& Martin, A. J. (2014). Personal best (PB) and 'classic' achievement goals in the Chinese context: Their role in predicting academic motivation, engagement, and buoyancy. Educational Psychology: An International Journal of Experimental Educational Psychology, 34, 635-658. https://doi.org/10.1080/01443410.2014.895297

Zimmerman, B. J. (2000). Attaining self-regulation: A social cognitive perspective. In M. Boekaerts, P. R. Pintrich, \& M. Zeidner (Eds.), Handbook of self-regulation (pp. 13 -35). San Diego, California: Academic. https://doi.org/10.1016/B978-012109890-2/50031-7 
Alishahi, M. H., \& Ghanizadeh, A. 